\title{
Possibilidades e realidades em comunidades Quilombolas do Maranhão: o turismo como resgate da memória e identidade
}

Possibility and realities in Maranhão Quilombolas communities: tourism as a rescue of memory and identity

\section{Saulo Ribeiro dos Santos}

Professor Adjunto do Departamento de Turismo e Hotelaria da Universidade Federal do Maranhão - UFMA, São Luís/MA, Brasil

E-mail: saulosantosma@uol.com.br

\section{Angela Roberta Lucas Leite}

Professora do Departamento de Turismo e Hotelaria da Universidade Federal do Maranhão UFMA, São Luís/MA, Brasil

E-mail: angelarobertalucas@gmail.com

\section{Aurea Helena da Conceição Rocha}

Graduanda pelo Departamento de Turismo e Hotelaria da Universidade Federal do Maranhão - UFMA, São Luís/MA, Brasil

E-mail: aureahellena@hotmail.com

\section{Gabriela de Souza Barbosa}

Graduanda pelo Departamento de Turismo e Hotelaria da Universidade Federal do Maranhão - UFMA, São Luís/MA, Brasil

E-mail: barbosagabriela98@gmail.com 


\section{RESUMO}

Este trabalho é parte constitutiva de um projeto de pesquisa com foco na extensão em andamento desde 2018 que tem o intuito de resgatar as memórias identitárias de comunidades quilombolas do Maranhão situada no município de Cururupu, que de alguma forma vem se perdendo desde o declínio econômico das antigas fazendas e com o desinteresse dos jovens em perpetuar a história do lugar. Assim, objetiva-se neste estudo identificar realidades e possibilidades do desenvolvimento turístico em duas comunidades quilombolas em Cururupu como forma de resgate da memória e história do lugar. Utilizou-se como procedimentos metodológicos a pesquisa bibliográfica e documental. Caracteriza-se como descritiva e exploratória, com análise qualitativa das conversas informais com os moradores mais antigos durante a pesquisa in loco, pautados em estudos realizados por Aguirre (1997), Barretto (2007), Bosi (1987), Martins (2003), Meneses (1992), Polack (1992) e Rico Cánovas (2014). Os resultados iniciais constatam que a partir de um modelo de desenvolvimento do turismo cultural, este segmento seria capaz de contribuir para a manutenção da identidade local e ser um possível perpetuador sociocultural das identidades, memórias e histórias das comunidades quilombolas de Cururupu.

Palavras-chave: Comunidades quilombolas. Cururupu (Maranhão). Identidade. Memória. Turismo cultural.

\section{ABSTRACT}

This work is part of a research project focused on extension in progress since 2018 that aims to recover the identity memories of Maranhão quilombola communities located in Cururupu (Maranhão, Brazil) which has been lost since the economic decline of old farms and the disinterest of young people in perpetuating the history of the place. Thus, the aim of this study is to identify realities and possibilities of tourism development in two quilombola communities in Cururupu as a way to rescue the memory and history of the place. The methodological procedures used were bibliographic and documentary research. It is characterized as descriptive and exploratory, with qualitative analysis of informal conversations with older residents during on-site research, based on studies by Aguirre (1997), Barretto (2007), Bosi (1987), Martins (2003), Meneses (1992), Polack (1992) and Rico Cánovas (2014). The initial results shows that from a cultural tourism development model, this segment would be able to contribute to the maintenance of local identity and to be a possible sociocultural perpetuator of the identities, memories and histories of the quilombola communities of Cururupu.

Keywords: Quilombola communities. Cururupu (Maranhão). Identity. Memory. Cultural tourism. 


\section{INTRODUÇÃO}

A atual conjuntura global nos âmbitos ambiental, cultura, econômico e social é apontada por estudiosos da dinâmica capitalista e econômica de mercado por não responder mais aos desafios impostos pela globalização, causando "patologias" sociais, que se fazem necessárias apontar como alternativa para um novo modelo de desenvolvimento social e econômico com fins sustentáveis (Berkes, 1997; Cohen \& Arato, 1992).

Estas tais "patologias" (socioambientais; socioespaciais; sociopolíticas; socioculturais) (Dowbor, 1983; Max-Neef, 1986, 1993; Berkes, 1997; DouroJeanni, 1996; Sen, 2000; Santos, Souza, \& Silveira, 2002; Singer, 2002; Sachs, 2003, 2004) são encontradas em seu extremo principalmente em países menos desenvolvidos e territórios que possuem baixo índice de desenvolvimento humano, como o caso do estado do Maranhão, que tem também o segundo pior Índice de Desenvolvimento Humano (IDH) do país, ficando atrás apenas de Alagoas ${ }^{1}$.

O turismo, sendo um dos principais vetores de resgate cultural conforme afirma Barretto (2007) e por ser uma atividade que, quando planejada, considera "o compromisso ético, de respeito e engajamento de 'quem está' e de 'quem vem' e o intercâmbio real entre os sujeitos 'que recebem' e os que 'são recebidos' e, destes, com o ambiente no qual interagem (Irving, 2009, p. 116)", permite desfrutar de um intercâmbio positivo de experiências entre turistas e autóctones, proporcionando o "encontro" entre identidades, de compartilhamento e aprendizagem mútuos, em que o visitante tem uma atitude participativa durante sua viagem, beneficiando o desenvolvimento local, mas respeitando os hábitos e as manifestações culturais. Por outro lado, a comunidade tem a possibilidade de consolidar sua identidade coletiva e gerar novas estratégias relacionadas ao desenvolvimento socioeconômico e cultural (Irving, 2009).

Parte-se do pressuposto de que comunidades que residem em áreas de quilombos ${ }^{2}$ são consideradas, em sua maioria, territórios culturais "em função de sua existência em núcleos relativamente isolados na malha geográfica regional" (Oliveira \& Marinho, 2005, p. 334) e buscam o (auto) reconhecimento identitário e afirmação sociocultural, já que o isolamento geográfico geralmente provoca problemas socioeconômicos que contribui para o esquecimento destas comunidades e também certa exclusão das políticas públicas (Almeida, 2013).

\footnotetext{
${ }^{1}$ Recuperado em 11, abril, 2019, de https://cidades.ibge.gov.br/brasil/ma/pesquisa/37/30255?tipo=ranking.

2 Definição de quilombo: "a unidade básica de resistência do escravo. Pequeno ou grande, estável ou de vida precária, em qualquer região em que existia a escravidão, lá se encontrava ele como elemento de desgaste do regime servil" (Moura, 1981, p. 87).
} 
No Maranhão, a discussão sobre (auto) reconhecimento de comunidades quilombolas, bem como a titulação de suas terras é antiga, mas não resolvida, camuflada pelas disputas de terras, grilagens e a própria história do negro em nosso Estado (Almeida, 2013). Portanto, fazse necessário ampliar a discussão sobre o negro no Maranhão, pois:

Os estudos relacionados à trajetória do negro livre maranhense pós-abolição ainda são poucos, daí ser este um campo que ainda oferece grandes possibilidades de pesquisas, ampliando dessa forma o conhecimento produzido acerca do assunto, o que certamente contribuirá para o enriquecimento da historiografia maranhense (Almeida, 2013, p. 1, grifo nosso).

O Maranhão tornou-se um território prioritariamente negro devido à intensa escravidão ocorrida nos séculos XVIII e XIX, consequente da vinda de negros africanos, que escravizados, ocuparam as terras do estado, e, consigo trouxeram sua cultura que aos poucos foi incorporada ao território maranhense (Projeto Vida de Negro, 2002). Vale ressaltar que dentre os estados brasileiros, "o Maranhão é o estado que apresenta o maior número de comunidades entre as recenseadas, sem incluir aquelas que ainda não tomaram conhecimento de seus direitos (Araújo, 2009, p. 58, grifo nosso).

Dados do IBGE (2018) apontam que $74 \%$ da população do estado do Maranhão é negra, sendo o estado do Nordeste que concentra o maior número de comunidades quilombolas (CQ) e comunidades remanescentes de quilombos reconhecidos (CRQR), com 734, conforme a Fundação Cultural Palmares (FCP, 2018) $)^{3}$ É o caso das comunidades quilombolas do município de Cururupu, mais especificamente as comunidades de Entre Rios ${ }^{4}$ e Aliança ${ }^{5}$ situadas a $18 \mathrm{~km}$ da sede do município, ambas certificadas pela FCP em 2005 e 2010, consoante Portal Brasileiro de Dados Abertos ${ }^{6}$.

Em sua grande maioria, as comunidades de quilombo, como as citadas acima, não estão preparadas para receber o turista,

[...] seja pela deficiência de equipamentos e objetos que servem de apoio à sua prática social, seja por carência de preparação da coletividade, o turismo será uma atividade meramente econômica que não reproduz benefícios socioculturais em comunidades que se esforçam em abrir suas portas para visitação (Oliveira \& Marinho, 2005, p. 342).

\footnotetext{
${ }^{3}$ A Fundação Palmares, órgão vinculado ao Ministério da Cultura voltado para a preservação da cultura afrobrasileira. A certificação da Fundação é o primeiro passo para titularização da terra, que é feito pelo Instituto Nacional de Colonização e Reforma Agrária (Incra).

4 Identidade Quilombola - 1.255; Certificada pela Fundação Cultural Palmares sob o processo 01420.001629/2010-10 (Fundação Cultural Palmares, 2018).

${ }^{5}$ Em novembro de 2009, a Presidência da República expediu o Decreto declarando a área de interesse social para fins de desapropriação (Incra, 2013).

${ }^{6}$ Dados recuperados em 18, abril, 2019, de http://dados.gov.br/.
} 
Contudo, já se é pensado o turismo para estas comunidades, conforme rege a política estadual de turismo, que pretende transformar o polo turístico Floresta dos Guarás no qual está inserido o município de Cururupu em:

Um modelo em referência de valorização da interação entre o homem e natureza
amazônicos, das formas de vida derivadas e da cultura tradicional, de conhecimento
e proteção a este ecossistema, que seja o motivo em torno do qual se desenvolvem
os programas e atividades que propiciem aos visitantes recompensadoras
experiências de base comunitária (Maranhão, 2012, p. 202).

Nesse sentido, questiona-se de que forma o turismo cultural pode se tornar uma ferramenta de valorização e propagação da memória e da identidade local de comunidades quilombolas em Cururupu (Maranhão), em especial as comunidades quilombolas de Aliança e Entre Rios, além de estimular o desenvolvimento econômico e social desse local? Assim, objetiva-se no presente trabalho relatar as experiências vivenciadas durante as visitas em duas comunidades quilombolas de Cururupu, tendo o turismo como fator de valorização e propagação da memória e identidade local, e possível propulsor para o desenvolvimento sociocultural.

Este trabalho soma-se às pesquisas que estão sendo desenvolvidas no polo Floresta dos Guarás no Maranhão, que reúne outras comunidades (remanescentes) quilombolas, além de fortalecer os estudos do Grupo de Pesquisa Turismo, Cidades e Patrimônio direcionados ao turismo cultural. Acredita-se que a partir dos resultados iniciais alcançados, estes tornam-se relevantes para a construção de uma base referencial sobre quilombos do Maranhão até então temática pouco pesquisada conforme descrito por Almeida (2013) e Projeto Vida de Negro (2002).

Esta pesquisa contribui para o conhecimento e entendimento sobre o passado das terras quilombolas de Aliança e Entre Rios, e também para a construção da memória destes locais, a partir dos relatos dos moradores, contribuindo assim, para a propagação da história do lugar que é pouco divulgada e registrada.

$\mathrm{O}$ artigo está dividido em quatro partes. O primeiro engloba a introdução com breve justificativa e contextualização da problemática e do objetivo do estudo. Em seguida, apresenta-se a metodologia com os métodos e técnicas utilizados para alcance do objetivo apresentado, assim como as fases da pesquisa. No terceiro item, traz-se a tona a discussão dos resultados obtidos com a pesquisa. E encerra-se com as considerações finais. 


\section{METODOLOGIA}

Para alcance do objetivo, referendou-se na bibliografia do projeto. A fonte bibliográfica está pautada em autores do turismo cultural como Barretto (2007, 2009), da memória em Bosi (1987), Meneses (1992), Polack (1992), da identidade Aguirre (1997) e Martins (2003) e do patrimônio cultural Rico Cánovas (2014). Fez-se levantamento documental sobre as comunidades quilombolas de Aliança e Entre Rios, principalmente os originais de registros de cartório das antigas fazendas, assim como os documentos emitidos pela Fundação Palmares de reconhecimento das áreas quilombolas.

Caracteriza-se como uma pesquisa descritiva e exploratória (Dencker \& Viá, 2001; Lakatos \& Marconi, 2002), pois se descreve as características do tema específico e também por não se ter muita informação sobre o tema em si, o que possibilitou novas descobertas sobre a história destes lugares, já que há poucos materiais publicados sobre o turismo e os quilombos maranhenses, principalmente nas bases de dados como Redalyc e CAPES. Na pesquisa de campo realizada nos meses de fevereiro e março de 2019, observou-se in loco o cotidiano dos quilombolas, os quais foram registrados em um diário de campo (Dencker \& Viá, 2001), levando em consideração a vida diária dos residentes quanto ao dia a dia dos mesmos. Nesta ação de campo e anotações, verificou-se aspectos econômicos, ambientais, sociais e culturais, assim como a participação em diversas atividades do cotidiano das comunidades como confecção de artesanato, produção de farinha, cachaça e bolo, roça e rodas de tambor de crioula. Tudo foi coletado através de imagens fotográficas, anotado em diário de campo, além de gravações das conversas informais com os moradores das comunidades pesquisadas (Lakatos \& Marconi, 2002).

Através de técnicas padronizadas de coletas de dados, aplicou-se questionário semiestruturado (baseado nos modelos de Irving, 2009; Oliveira, 2005; Rico Cánovas, 2014). A aplicação do questionário teve como objetivo levantar dados que permitissem identificar as dimensões ambientais, culturais, econômicas e sociais dos quilombos, assim como aspectos sobre o turismo na localidade.

Os moradores foram escolhidos mediante critério "idade", sendo os quatro mais antigos de cada quilombo (amostra não probabilística) participaram da coleta de dados, quantidade esta que se conseguiu fazer um levantamento sobre a historicidade do lugar (Quivy \& Champenhoudt, 2005) e também acessar documentos e registros relevantes para a composição do trabalho.

Quanto à escolha das comunidades quilombolas se deu pelos seguintes critérios: 
a) relevância histórica e social - por se tratar de territórios do fim do século XIX e início do século XX com uma história marcada por lutas e resistências das comunidades tradicionais quilombolas e por ter na coletividade da terra a pose por meio da herança dos descendentes de antigos donos (Cruz, 2012);

b) tradicional expressão econômica - produção de farinha d’água e outros produtos derivados como: tapioca de bolo e tapioca de goma e farinhão (farinha de grossos caroços); cultivo da agricultura e piscicultura (Cruz, 2012);

c) importância turística - pertencente ao polo turístico Floresta dos Guarás (Cruz, 2012).

A análise das anotações, os resultados dos questionários e as gravações, foram transcritas para o Excel e analisadas individualmente de forma qualitativa com base nos preceitos de Bardin (1995) e Orlandi (2000) quanto a análise do conteúdo e do discurso de cada um dos residentes entrevistados. Para Bardin (1995, p. 28) a análise do conteúdo tem como objetivo "[...] rejeitar a tentação da sociologia ingênua, que acredita poder apreender intuitivamente as significações dos protagonistas sociais, mas que somente atinge a projeção da sua própria subjetividade”. E que “[...] essa atitude de vigilância crítica exige o rodeio metodológico e o emprego de técnicas de ruptura”. A partir do agrupamento das informações do campo pôde-se cruzar os dados para então descrever a linha do tempo sobre a memória dos quilombos, e também as entrevistas corroboraram para identificar possibilidades do turismo nas comunidades quilombolas pesquisadas.

\section{O TURISMO COMO PRESSUPOSTO PARA O RESGATE E MANUTENÇÃO DA HISTÓRIA E MEMÓRIA DOS QUILOMBOS DE CURURUPU}

Cururupu, município do nordeste brasileiro localizado no estado do Maranhão ocupa uma área de 2.631 hectares (Mapa 1). Já foi um dos maiores territórios brasileiro de exploração da mão de obra escrava oriunda da África entre os séculos XVIII e XIX (Cruz, 2012). Resultado de um passado de confluências culturais e identitárias, o Maranhão é composto por diversas raças, dentre elas a negra que ocuparam/herdaram as antigas fazendas de Cururupu oriundas da corrente de fazendeiros que vieram de Guimarães (Maranhão), durante o processo de expansão e ocupação do litoral ocidental maranhense, e a partir de então, foram surgindo às fazendas de plantação de cana de açúcar como o caso de Aliança. Já a história de Entre Rios perpassa também pela herança da fazenda dos descendentes dos antigos donos, onde os filhos dos bastardos senhores de engenho tiveram filhos com as 
escravas, e quanto estes chegavam a fase adulta, casavam, e lhes fora dada as terras para produzirem, juntamente com escravos para começarem a vida de forma independente, e assim, Entre Rios foi se constituindo como terra de negro.

As comunidades quilombolas de Aliança e Entre Rios possuem histórias similares, ambas estão datadas dos séculos XIX e início do século XX, e tem na coletividade da terra a pose por meio da herança dos descendentes de antigos donos (Cruz, 2012). As terras eram antigas fazendas ${ }^{7}$ que foram deixadas para os descendentes e atualmente possuem a documentação de entrega das terras a eles.

${ }^{7}$ A fazenda Aliança possui 5.708 hectares e a fazenda Entre Rios possui aproximadamente 3000 hectares. 


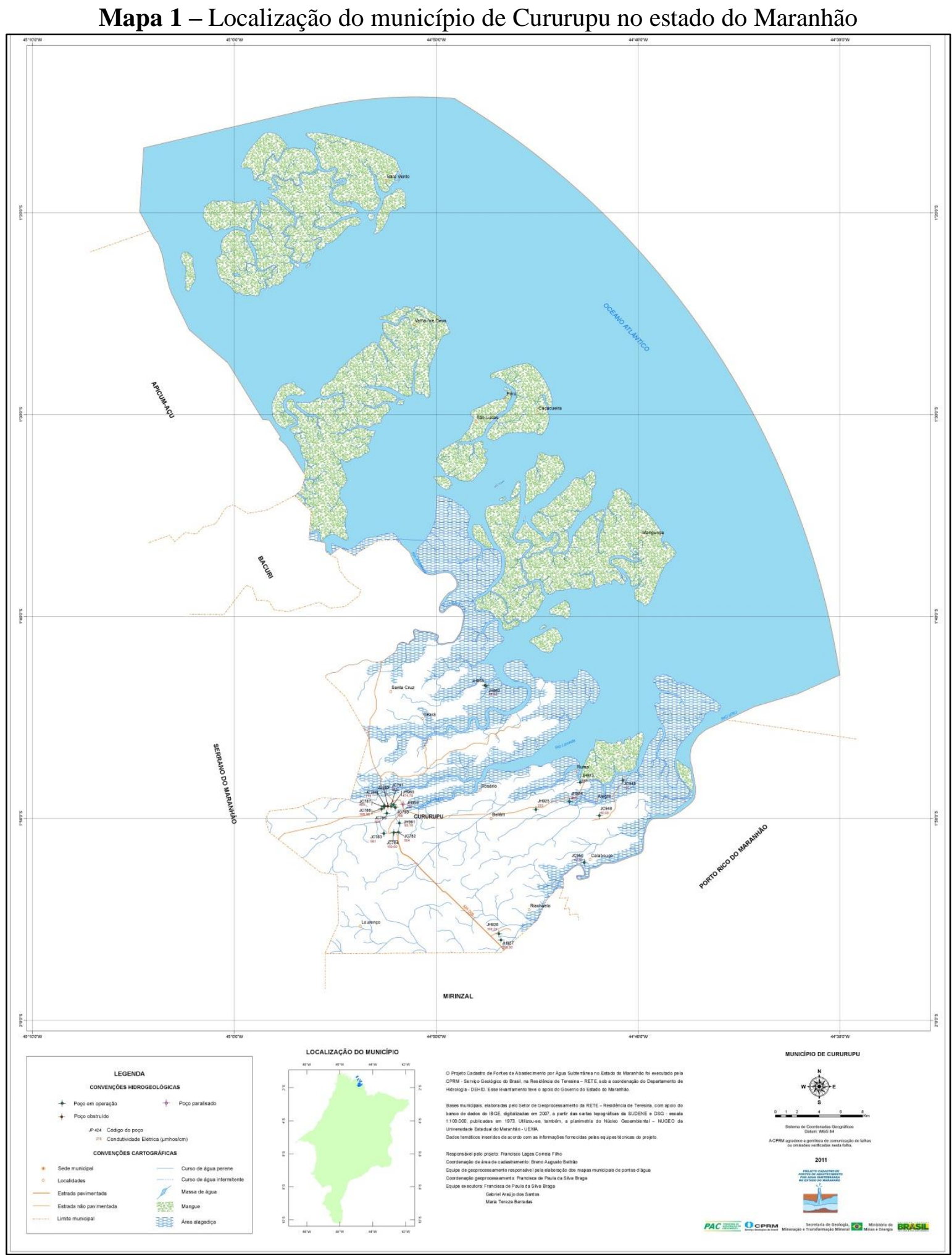

Fonte: Ministério de Minas e Energia, 2019.

Quilombos são reconhecidos como locais de forte tradição cultural, "isolamento" territorial, e de pouco contato com o urbano, o qual deve-se pensar modelos de desenvolvimento (nos mais diversos setores) que auxiliem e contribuam para a manutenção da tradição cultural, e preservação da memória (Augé, 2001; Barretto, 2009). Portanto, o viés do 
turismo cultural é uma alternativa para a sustentação da história e fortalecimento da identidade cultural, como apresenta Barretto (2007, p. 57, tradução nossa):

[...] reconhece que o turismo pode ser um meio eficaz para a preservação do patrimônio e o diálogo entre as culturas. Também reforça a necessidade de aprofundar a reflexão sobre a relação entre turismo, cultura e desenvolvimento, incluindo as relações entre visitantes e visitados, as quais deve prevalecer o equilíbrio para preservar a diversidade e promover o desenvolvimento local.

Para que comunidades tracionais quilombolas, como os casos de Aliança e Entre Rios possam valer-se dos impactos positivos que a atividade turística promove no âmbito cultural, principalmente no que tange ao fortalecimento da identidade cultural e memória do lugar é necessário que aconteça benefícios a comunidade receptora por parte do turismo, e não somente para o governo e setor privado como esclarece Barretto (2007). Esta sociedade quilombola apontada pelos entrevistados vem "sofrendo" com o desinteresse dos jovens em propagar a cultura negra dos quilombos, e, portanto, esta identidade pode desaparecer e se dissolver em uma sociedade globalizada e midiática. Por isso, Castells (2000) e Bauman (2005) afirmam sobre a importância de um processo de construção de significados que adotem as inter-relações culturais, sob uma base permanente onde cada membro do quilombo, por exemplo, compreenda seu papel na preservação da identidade cultural.

Vale ressaltar que a proposta do projeto de pesquisa em desenvolvimento é contribuir para o fortalecimento da cultura quilombola, através do turismo e da ecossocioeconomia, envolvendo a comunidade no processo de construção, preservação, valorização e propagação da memória e identidade local.

Estudos de Bosi (1987) esclarecem que é através da memória que se pode revisitar o passado e entender a dinâmica social, sendo a memória aqui entendida como uma "construção social, formada por imagens necessárias para os processos de constituição e reforço da identidade individual, coletiva e nacional” (Meneses, 1992, p. 22). Assim, busca-se compreender a dinâmica social dessas comunidades a partir do contexto histórico e dos relatos de seus moradores.

De acordo com o entrevistado A, a comunidade quilombola de Aliança já foi considerada um grande entreposto na região, inclusive sendo reconhecida como uma das áreas industriais mais prósperas do Brasil entre 1886 e 1965, possuindo zona comercial e portuária, além de ter abrigado uma grande área de plantação de cana de açúcar e um engenho que produziu a famosa cachaça "Aliança".

De acordo com o relato de um morador "o engenho chegou a ter aproximadamente 300 funcionários", tornando-se um dos maiores em todo o Brasil durante a século XIX e XX. 
Além disso, contava com "uma pista de pouso com voos ligando Cururupu/Aliança/São Luís”, o que beneficiava o escoamento e introdução de produtos na região. Pelo porto eram exportados o açúcar e a cachaça para diversos lugares do mundo, e por este também chegavam os produtos que eram vendidos na zona comercial. Todo o maquinário do engenho foi fabricado na Inglaterra, pela empresa Derby Fletcher \& Stewart Ltd England E $^{8}$ compreendia quatro caldeiras, trilhos, roda de esteira, entre outros (Figura 1).

Figura 1 - Ruínas do maquinário do antigo engenho de cana no quilombo Aliança

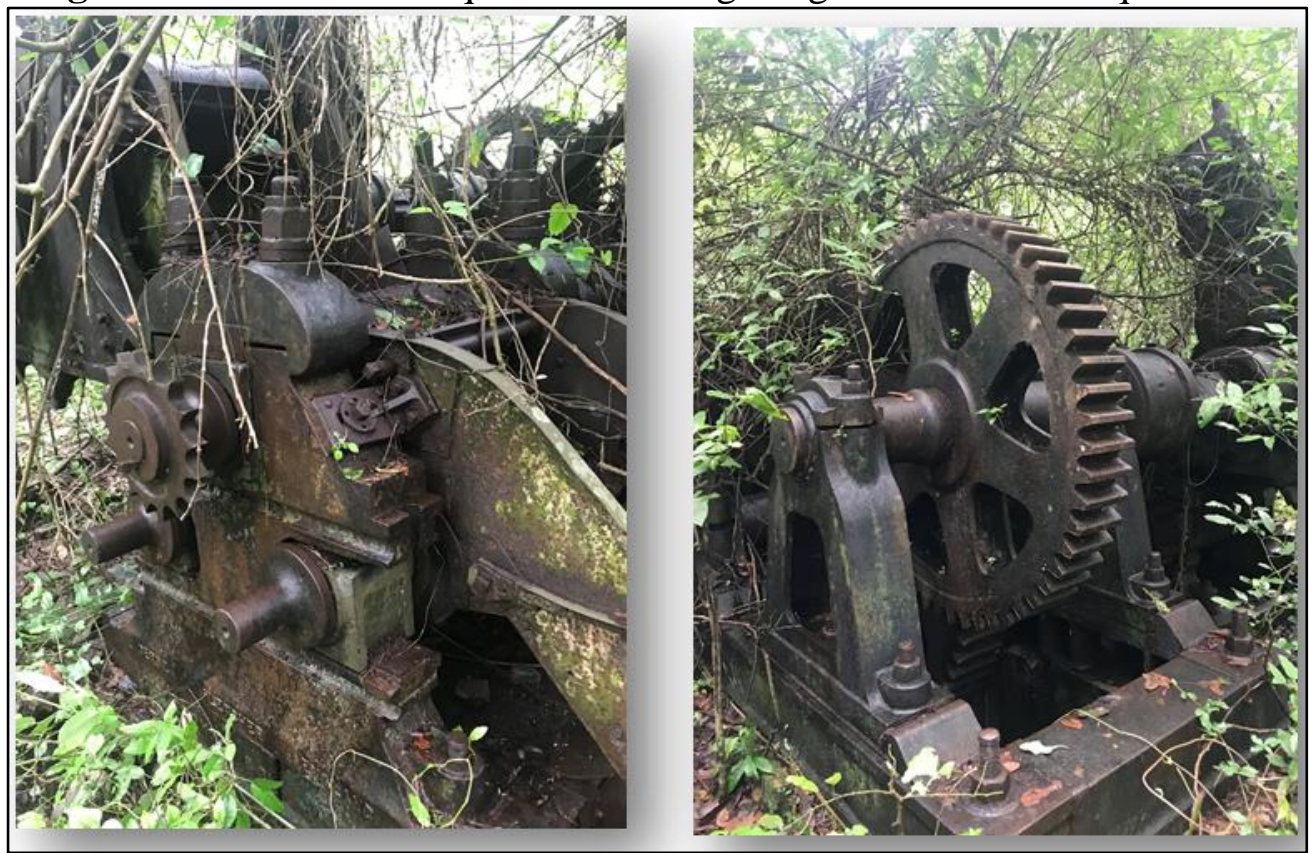

Fonte: Elaborado pelos autores, 2019.

A cachaça produzida no engenho ficava armazenada nos quatorze tanques e de lá eram engarrafados e exportados. Para um dos moradores mais antigos de Aliança,

\begin{abstract}
O engenho era muito avançado pra época, com alta tecnologia, movido a vapor, e toda a força da água que fazia o engenho funcionar veio de uma alteração manual (por mais de $2 \mathrm{~km}$ ) realizada num desvio de curso do rio que chegava até as caldeiras e faziam as rodas rodarem e moer toda a cana que passava duas vezes no maquinário, e o bagaço seco ia pra caldeira pra dar pressão no forno e produzir o vapor, que também era abastecido por madeira que chegavam nos trilhos instalados na época (Entrevistado B).
\end{abstract}

Na concepção de todos os entrevistados, atualmente, o maior legado histórico que faz parte da memória de Aliança é o antigo engenho de açúcar, que devido ao declínio em decorrência da concorrência com o estado de Pernambuco chegou à falência, restando hoje, somente alguns maquinários, a caldeira e os tanques. $\mathrm{O}$ acesso a esta antiga indústria é pela

\footnotetext{
${ }^{8}$ A George Fletcher \& Co foi fundada por George Fletcher em 1830 em Londres (Inglaterra) para produzir máquinas de refino de açúcar (Archives Hub, 2019, s/p, tradução nossa).
} 
mata adentro, e não existe nenhum trabalho de resgate da história (tanto pelo poder público quanto pela associação dos moradores). E somente os moradores mais antigos, que vivenciaram todo este momento é que ainda guardam as histórias e boas lembranças do período áureo da fazenda Aliança.

A comunidade quilombola de Entre Rios já possui uma história diferente, sem engenhos com maquinário inglês, ou seja, sem tecnologias modernas. O antigo engenho era movido pelo carro de boi (atualmente em ruínas), e o transporte de toda a produção era feito por tração animal. Mesmo ambas as comunidades serem oriundas de antigas fazendas e próximas territorialmente, Entre Rios é menor em termos de população e residências, fazendo com que o conceito de coletividade e cooperação impere neste território negro.

Características como união são fortemente percebidas em Entre Rios, que sempre se reúnem para debater e discutir questões relacionadas à comunidade. Um dos fortes aspectos mantidos pela comunidade são as manifestações culturais, que em Aliança já não está tão presente. Em Entre Rios há o predomínio do tamborim e tambor de crioula (Figura 2).

Figura 2 - Tambor de Crioula na comunidade quilombola Entre Rios

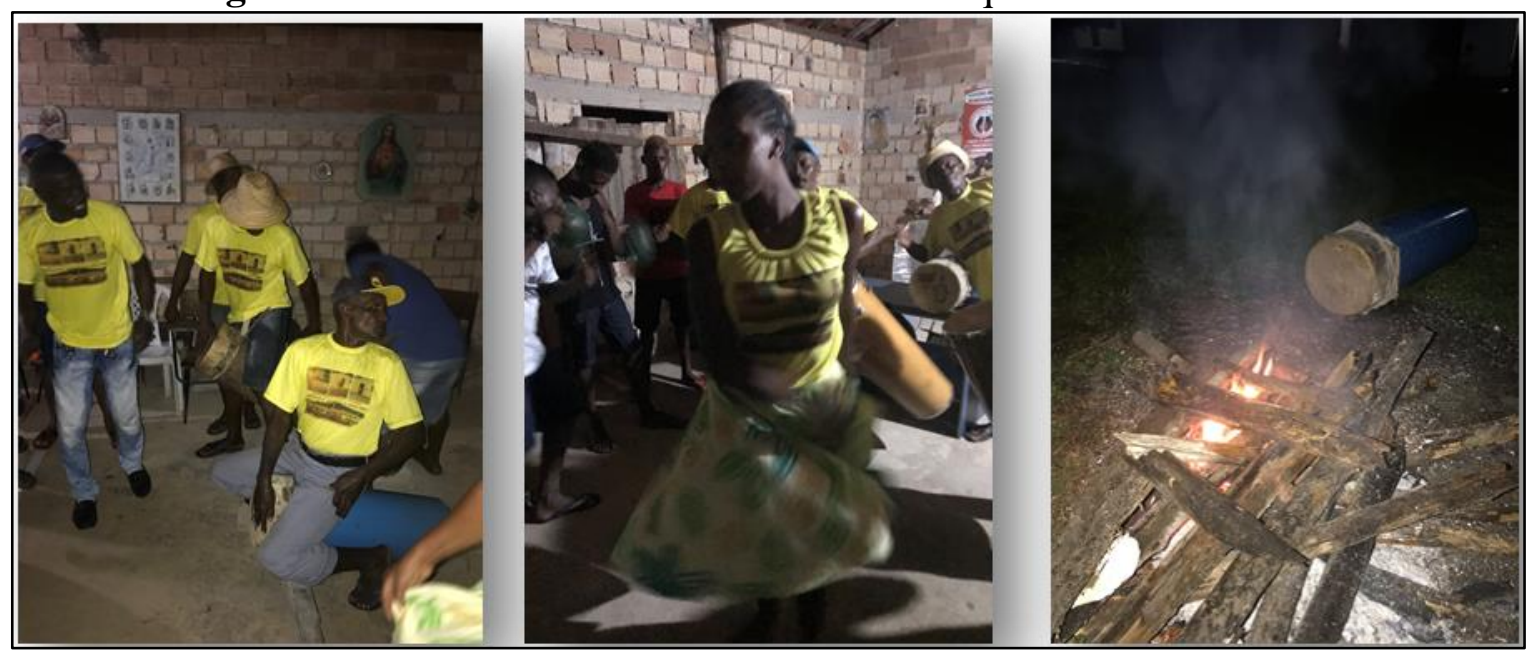

Fonte: Elaborado pelos autores, 2019.

O tamborim possui um toque cadenciado que se assemelha ao boi de zambumba ${ }^{9}$ em que os homens tocam e as mulheres dançam igual ao tambor de crioula, mas conforme depoimento do entrevistado D de Entre Rios, existem diferenças, pois:

\footnotetext{
${ }^{9} \mathrm{O}$ sotaque de zabumba ou, Guimarães - originário da cidade de Guimarães - distingue-se pela zabumba, tocada apoiada em varas de madeira, e pelo tamborinho. Entre os personagens destaca-se o "rajado", que veste saiotes e golas bordados com motivos da fauna, da flora ou da religião, sendo caracterizado pelo chapéu de copa na forma de cogumelo, adornada com bastas fitas coloridas que descem até a altura do tornozelo e uma pequena pala frontal bordada geometricamente. Os vaqueiros apresentam a mesma indumentária, mas o chapéu é menor. As índias, chamadas de tapuias, se diferenciam dos outros sotaques pela peruca de longos cabelos (de ráfia ou nylon), encimada por um adorno de papelão (numa forma entre uma coroa e um cocar), e por vestirem um saiote
} 
Com o tambor de crioula realmente, é o começo dos escravos dos negros é o tambor de crioula, agora o tamborim é encostado logo no tambor de crioula, isso aí é só uma família é só uma raiz é a festa dos negros, dos escravos na época dos escravos. Isso aqui pode dançar inté agarrado, tem valsa tem tudo [...] Foi passado da minha avó pra minha mãe, aí quando minha mãe 'viajou' eu fiquei, mais acho que passou de alma por que é um dom que eu nem sabia, e eu fico muito feliz por esse dom que Deus me deu.

Portanto, a diferença do tamborim para o tambor de crioula é que quando se toca tambor pode dançar até "agarrado", sendo uma manifestação cultural repassada de geraçãoem-geração. Esses tambores e tamborins quebram o silêncio e sossego da comunidade em dias de festas. "O silêncio em Entre Rios é tão grande que dá pra se conversar a distância, $e$ se rompe com o som dos tambores, o que deixa a comunidade mais alegre e festiva", conforme ressalta o entrevistado E. O festejo de São Benedito (santo protetor da comunidade, também conhecido como padroeiro) acontece anualmente no mês de agosto, e dura cerca de quatro dias com muita música, dança, bebida e comida. No decorrer dos dias são realizadas missas, procissões e almoço comunitário, sendo aberta para visitantes. Contudo, o último dia a festa é "interna", somente para os moradores da comunidade quilombola.

Identificou-se nos entrevistados o sentimento de pertencimento quanto à identidade cultural, os costumes e tradições dos quilombolas de Entre Rios, principalmente nos mais velhos, o que acaba por vezes se perdendo em virtude de os jovens não manterem essas tradições. De acordo com o entrevistado E, isso acontece "porque muitos jovens desta comunidade têm vontade de abandoná-la não por falta de respeito ou admiração por sua terra e história, mas por falta de oportunidades de trabalho e educacionais", já que o quilombo não possui escola, e, portanto, os jovens precisam se deslocar em ônibus ou pau-de-arara para Cururupu, e quiçá empregos para todos.

Apesar disto, os moradores consideram a comunidade rica por ter solo fértil para o roçado e hortas. Além disso, há uma pequena produção de artesanato como peças de crochê e retalhos, cofos e abanos com palha, fora suas danças típicas, o tambor de crioula e o tamborim que é natural e exclusivo da comunidade.

O modo de vida das comunidades quilombolas de Aliança e Entre Rios é similar, pois boa parte trabalha na "vila" jovens e crianças, em sua maioria, estudam em Cururupu e retornam para os quilombos e continuam suas atividades educacionais. Poucos são os que auxiliam os pais na roça. $\mathrm{O}$ sentimento de pertencimento ao lugar existente entre os entrevistados dos quilombos Entre

de tecido na forma de tiras, um bustiê, às vezes uma meia-longa de crochê, elas não usam adereços de penas (Albernaz, 2013, p. 8).

${ }^{10}$ Como eles intitulam a cidade de Cururupu. 
Rios de Aliança une-se às concepções de Aguire (1997), Bosi (1987) e Martins (2003) que compreendem como uma "paixão" pela terra, que reflete na memória e história acontecida nestes territórios.

Dourojeanni (1996) esclarece que um dos preceitos da sustentabilidade no território está ligada aos aspectos de cooperação e integração da comunidade, algo não percebido nas visitas realizadas no quilombo Aliança, devido inúmeros aspectos, dentre eles: adensamento populacional, inclusive com pessoas de outras localidades, proximidade com a rodovia MA $006(1 \mathrm{~km})$, desinteresse pela história do lugar, entre outros aspectos. Fatos estes que se agravam também com a criminalidade, tráfico, violência existentes em Aliança como afirmou o entrevistado B.

Com relação à cadeia produtiva, em ambos quilombos existem a casa de farinha, sendo que no Aliança a produção é em menor quantidade se comparado com Entre Rios, que produz tanto para consumo próprio, quanto para comercialização. Vale destacar que nesses ambientes tem o forno, o pilão, ralador (caititu), tanque, cocho e forno de torrefação, elementos estes que podem estreitar a relação com a atividade turística, uma vez que a cultura popular está intimamente associada ao ambiente e às transformações que nele ocorre (Rico Cánovas, 2014). Barretto (2007, 2009) ressalta que o turismo pode ser motivado pela história, o cotidiano, o artesanato, desde que relacionado a algum aspecto da cultura humana. Ou seja:

\begin{abstract}
A identidade se encontra ligada ao desenvolvimento de um lugar e vai se originando graças a sua evolução. Toda comunidade gera costumes, tradições, leis, etc., para crescer e avançar ao longo do tempo, que compõem e formam sua cultura. Graças à cultura, a comunidade é capaz de continuar desenvolvendo-se. Por isto, a identidade local de um povo pode ser caracterizada por sua cultura, e por seu desenvolvimento em definitivo (Ortega, 2018, p. 254, tradução nossa).
\end{abstract}

Assim, tem-se o turismo cultural que "proporciona experiências de valorização dos bens culturais além de estimular ações de preservação patrimonial, aproximando a comunidade de seus lugares de memória e manifestações tradicionais" (Carvalho, 2011, p. 8). Por compreender este aspecto, vê-se este segmento como um norteamento para ser trabalhado/desenvolvido nas comunidades quilombolas referenciadas nesta pesquisa, por se tratar de uma forma de perpetuar as práticas seculares de grupos sociais, ou seja, é um "conhecimento tradicional que deve ser sistematizado e organizado para a informação ao visitante" (Ministério do Turismo, 2010, s/p.). A autenticidade é um fator relevante para o turista cultural como esclarece Rico Cánovas (2014, p. 369) “[...] a busca pela autenticidade está na base da experiência turística, e constitui um argumento simples para explicar a realidade do turismo contemporâneo". 
Dentre os entrevistados identificou-se que os residentes da comunidade quilombola Entre Rios possuem maior interesse em fortalecer a identidade cultural do local, pois eles possuem diversos trabalhos, oficinas e cursos a partir da associação dos moradores que valorizam a cultural local, trabalhando e integrando a comunidade num processo de pertencimento, além de uma tentativa de enquadrar os jovens sobre a importância da memória e história do lugar como esclarecem Bosi (1987), Pollack (1992) e Nora (1993).

O objetivo das ações em Entre Rios é repassar a herança das antigas populações e conservar o patrimônio cultural para as gerações futuras (Berkes, 1997). Isto sendo trabalhado de forma contínua é possível através do turismo, onde ocorre a troca de informações, se propagar e então, a memória do lugar permanecer acessa e evidente. Reforça-se também este aspecto na comunidade quilombola de Aliança em que o turista cultural poderá conhecer e possivelmente propagar a história do engenho de açúcar, além de resgatar e potencializar o sentimento de pertencimento do lugar (Rico Cánovas, 2014).

O patrimônio cultural tem sido considerado como um motor de desenvolvimento territorial, que de acordo com diversas perspectivas, entre elas o turismo, tem gerado, implantado e desenvolvido novos usos recreacionais y lúdicos para os recursos patrimoniais localizados em espaços turísticos, que por sua vez, se encontram em diferentes fases de desenvolvimento. [...] argumento importante para o uso turístico dos elementos patrimoniais desde diferentes perspectivas. Em primeiro lugar deve-se levar em consideração alguns casos como argumento relevante dos processo de renovação e qualificação dos espaços turísticos (Rico Cánovas, 2014, p. 316).

Assim, o turismo em comunidades quilombolas deve ser pensado e analisado levando em consideração as realidades locais como limitações, potencialidades, nível de educação, interesse, disposição, participação, entre outros aspectos, pois, caso não seja planejado adequadamente, este fenômeno pode ser avassalador. Pois, como afirma Dourojeanni (1996) se ajusta necessário o desenvolvimento de gestão sustentável dos recursos patrimoniais culturais. A esse respeito, Rodovalho, Fonseca e Sousa (2010, p. 12) ressaltam que

[...] Tanto turistas como moradores locais confrontam suas identidades e sua cultura quando tratamos de deslocamentos humanos para o lazer. No morador local, ele despertaria um sentimento de pertencimento e de orgulho, de preservação. No turista, ele suscita, em um primeiro momento, a curiosidade, o desejo de conhecer, de sair de seu contexto e se encontrar com o outro e sua diversidade.

A concepção acima esclarece que "[...] onde se dá a atividade turística, de uma forma ou de outra dá-se o despertar de uma consciência de lugar, de ser local e de um sentimento de orgulho, uma visão de povo [...]" (Martins, 2003, p.45). Todavia, para que todo este processo possa acontecer é necessária a realização de ações que antecedam o turismo, como: 
a) Sensibilização dos jovens (principalmente) através das novas tecnologias, criando aplicativos ou plataformas digitais onde eles possam aprender e propagar a cultura local dos antepassados e atuais, criando assim um ambiente criativo e inovador, mas ao mesmo tempo educacional e cultural;

b) Mapeamento das realidades locais, pois, cada comunidade quilombola diferese quanto aos aspectos de sociedade, identidade, tradição, memória, pertencimento e cooperação;

c) Orientação sobre o que é o turismo, para que eles possam entender e então decidir se desejam que esta atividade seja realidade na comunidade ou não;

d) Criar um comitê gestor do turismo na comunidade para de forma permanente possam debater questões relacionadas ao assunto, mensurando os impactos que podem ser ocasionados pela atividade.

Ou seja, desenvolver um trabalho de enraizamento da memória e do pertencimento através do turismo (Barretto, 2007, 2009; Carvalho, 2011; Rico Cánovas, 2014) de maneira que venha contribuir na manutenção e fortalecimento da identidade (Castells, 2000) e singularidade local requer cuidados quanto ao tratamento e inserção do tema na comunidade, para que haja um interesse da comunidade numa construção contínua na formação e na consolidação das identidades locais e individuais (Augé, 2001).

Ratifica-se que a aplicabilidade de um modelo de turismo cultural pode contribuir para realçar a diversidade cultural e difundir os conhecimentos e vivências das comunidades quilombolas de Aliança e Entre Rios.

O turismo cultural em essência, também pode ser denominado de turismo de resgate,
visto que, essa forma de turismo voltado para a área cultural visa perceber - as
atividades turísticas relacionadas à vivência do conjunto dos elementos
significativos do patrimônio histórico e cultural e dos eventos culturais, valorizando
e promovendo os bens materiais e imateriais da cultural (Ministério do Turismo,
2010, s.p.).

O território quilombola é um lugar onde se estabelecem os vínculos culturais da história de quem eles foram, são e deveriam ser. E é através da memória individual e coletiva que se recorre para manter o sentimento de pertencimento, aliado ao turismo cultural, ou seja, nestes territórios, dialogam-se a cultura enquanto expressão do lugar e da identidade, que Aguirre (1997) e Rico Cánovas, 2014 conceituam como patrimonialização, ou seja, a materialização dos costumes, tradições, modo de ser e viver de uma comunidade.

Entende-se aqui como patrimônio todas as esferas da natureza em que o homem vive e atua, que ele usa ou transforma para atender a suas necessidades matérias (de sobrevivência) e simbólicas (subjetivas, de satisfação, de conhecimento) e os bens 
culturais por ele produzidos, resultantes de sua ação no meio em que habita. Esses bens, materiais e imateriais, expressam a valorização do que fomos, do que somos e de onde estamos e, dessa forma, enquanto legado cultural para gerações futuras, expressam, consolidam e revelam a identidade de um povo (Rodovalho, Fonseca, \& Sousa, 2010, p. 12).

A visitação turística em comunidades quilombolas como Aliança e Entre Rios poderá garantir a manutenção dos laços identitários e do próprio resgate da memória, pois para Pollack (1992) estes se caracterizam como elemento que promove o sentimento de pertencimento à identidade, tanto individual quanto coletiva, assim como um fator de sentimento de continuidade e de coerência de uma determinada pessoa ou de um grupo em sua reconstrução de si.

\section{CONSIDERAÇÕES FINAIS}

A partir da exposição apresentada neste texto, pode-se concluir que o turismo cultural é capaz de contribuir para a preservação da diversidade cultural e difundir os conhecimentos e vivências das comunidades quilombolas de Aliança e Entre Rios, uma vez que o território quilombola é um lugar onde se estabelecem os vínculos culturais da história de quem eles foram, são e deveriam ser. E através da memória individual e coletiva que se recorre para acionar o sentimento de pertencimento, em que nestes territórios dialogam a cultura enquanto expressão do lugar e da identidade, de materialização dos costumes, tradições, modo de ser e de viver em comunidade.

O turismo enquanto fenômeno social, com uma demanda segmentada e crescente e no qual as motivações dos turistas são provenientes de diversos fatores, dentre eles o conhecimento de outras culturas, direcionados à ideia de civilização, erudição e lugar de memória tem encontrado na cultura, forma de ampliar as relações sociais, além de aprender e aprimorar o conhecimento, como o caso de visitação em áreas quilombolas.

A memória e identidade de um lugar, como dos quilombos Aliança e Entre Rios em Cururupu são reflexos de uma importante história do estado do Maranhão que ficou no passado, mas que através do turismo pode ser resgatada, preservada e repassada para outras gerações de acordo com o modelo de turismo a ser desenvolvido no lugar.

Fazer com que a comunidade quilombola seja protagonista de sua história e valorize cada vez mais o sentimento de pertencimento ao território quilombola através do turismo cultural é de muita valia e essencial para afirmação de contextos e modos de vidas, bem como a revalorização e revitalização do patrimônio cultural e da identidade coletiva. 
Aliança e Entre Rios, mesmo com singularidades e distanciamentos, tem na sua essência a alma negra e num mundo tecnológico onde a virtualização tornou-se real, é necessário humanizar o processo de desenvolvimento turístico, fazendo com que os jovens negros possam propagar a alma do lugar sem perder sua essência.

Portanto, a visitação turística em comunidades quilombolas como Aliança e Entre Rios poderá garantir a manutenção dos lações identitários e do próprio resgate da memória, proporcionando não somente àqueles que visitam experiências do modo de vida, tendo contato com os hábitos e costumes regionais, mas resgata a identidade desse povo que é incentivada pela presença do turista e estimula a produção e o desenvolvimento local. Porém, instiga-se que essa prática seja resultado da parceria entre o poder público, a iniciativa privada, os sindicatos regionais de trabalhadores rurais e outras instituições, que devem trabalhar em conjunto para identificar e estimular as potencialidades, capacidades e aptidões locais.

Vale ressaltar ainda que não se deve limitar apenas a promoção de políticas públicas de turismo, ou seja, de aumentar o fluxo de turistas e visitantes nessas comunidades, por exemplo, mas o incentivo de políticas sociais e educacionais que venha contribuir para a melhoria de qualidade de vida das populações receptoras.

\section{REFERÊNCIAS}

Augé, M. (2001). Rapports Entre Tourisme, Culture et Territoire. Turisme i Cultura. Debats del Congrés de Turisme Cultural. Saló Internacional del Turismo a Catalunya. Barcelona: Fundació Interarts.

Aguirre, A. (1997). Cultura y identidad cultural, introducción a la antropologia. Barcelona: Ed. Bardenas.

Albernaz, L. S. F. (2013). Dinâmicas do Bumba meu boi maranhense: classificação em "sotaques" e participação do público. Revista Olhares Sociais, 2(2), 3-24.

Almeida, M. C. P. (2013). O movimento quilombola na baixada ocidental maranhense: história, memória e identidade de comunidades remanescentes de quilombos em Pinheiro. Anais do Simpósio Nacional de História, Natal, RN, Brasil.

Araújo, D. D. (2009). Nós já estamos em cima desse chão: a questão da terra quilombola do Rio Grande-Bequimão-MA. Trabalho de Conclusão de Curso (Monografia), Universidade Estadual do Maranhão, São Luís, MA, Brasil.

Bardin, L. (1995). Análise de conteúdo. Lisboa: Persona.

Barretto, M. (2007). Cultura e turismo: discussões contemporâneas. Campinas: Papirus. 
Barretto, M. (2009). Turismo y cultura. Relaciones, contradicciones y expectativas. El Sauzal (Tenerife, España): Pasos, Revista de Turismo y Patrimonio Cultural. E-book, Colección PASOS Edita, 1.

Bauman, Zygmunt. (2005). Identidade. Rio de Janeiro: Jorge Zahar.

Berkes, F. (1997). Social systems ecological systems and property rights. In Hanna, S. et al. (Eds.). Right to nature: ecological, economics, cultural and political principles of institutions. Washington, DC: Island.

Bosi, E. (1987). Memória e sociedade: lembrança dos velhos. (2a. ed.). São Paulo: Editora da Universidade de São Paulo.

Brasil. Ministério do Turismo. (2010). Turismo cultural: orientações básicas. (3a. ed.) Brasília: Ministério do Turismo. Recuperado de http://www.turismo.gov.br/sites/default/turismo/o_ministerio/publicacoes/downloads_publica coes/Turismo_Cultural_Versxo_Final_IMPRESSxO_.pdf.

Carvalho, K. D. (2011). Lugar de memória e políticas públicas de preservação do patrimônio: interfaces com o turismo cultural. Revista Turismo Visão e Ação, 13(2), 149-165.

Castells, M. (2000). O poder da identidade. São Paulo: Paz e Terra.

Ortega, C. J. (2018). Una aproximación al concepto de identidad cultural a partir de experiencias: el patrimonio y la educación. Tabanque, 31, 244-262

Cohen, J, \& Arato, A. (1992). Civil society and political theory. Cambridge, Mass.: MIT Press.

Cruz, M. (2012). Comunidades quilombolas do município de Cururupu no Maranhão. Recuperado de http://patrimoniotradicional.blogspot.com.br/2012/07/comunidadesquilombolas-do-municipio-de.html.

Dencker, A. F. M., \& Viá, S. C. (2001). Pesquisa Empírica em Ciências Humanas (com ênfase em comunicação). São Paulo: Futura.

Dourojeanni, A. (1996). Reflexiones sobre estrategias territoriales para el desarrollo sostenible. Conferencia Cumbre sobre el Desarrollo Sostenible, 1996. Santiago de Chile: CEPAL. Recuperado de https://archivo.cepal.org/pdfs/Waterguide/LCG1944S.PDF.

Dowbor, L. (1983). A formação do $3^{\circ}$ mundo. São Paulo: Brasiliense.

Fundação Cultural Palmares. (2018). Comunidades remanescentes de quilombos. Recuperado de http://www.palmares.gov.br/comunidades-remanescentes-de-quilombos-crqs.

Irving, M. A. (2009). Reinventando a reflexão sobre turismo de base comunitária: inovar é possível? In: Bartholo, R., Sansolo, D. G., \& Bursztyn, I. (Eds.). Turismo de base comunitária: diversidade de olhares e experiências brasileiras. Rio de Janeiro: Letra e Imagem.

Lakatos, E. M., \& Marconi, M. A. (1999). Técnicas de Pesquisa: planejamento e execução de pesquisas, amostragens e técnicas de pesquisas, elaboração, análise e interpretação de dados. São Paulo: Atlas. 
Maranhão. Governo do Estado. (2012). Plano Maior 2020: plano estratégico de turismo do estado do Maranhão - relatório final. São Paulo: Chias Marketing.

Martins, C. (2003). Identidade, percepção e contexto. In Martins, C. (Ed.). Turismo, Cultura e Identidade. (4a. ed.). Rio de Janeiro: Record.

Max-Neef, M. (1986). La economia descalza: Señales desde el Mundo Invisible. Estocolmo, Buenos Aires, Montevideo: Nordan Comunidad.

Max-Neef, M. (1993). Desarrollo a escala humana: conceptos, aplicaciones y reflexiones. Montevideo: Nordan Comunidad, REDES.

Meneses, U. T. B. (1992). A história, cativa da memória? Para um mapeamento da memória no campo das ciências socais. Revista do Instituto dos Estudos Brasileiros, (34), 9-23.

Ministério de Minas e Energia. (2019). Recuperado de http://www.mme.gov.br/

Moura, C. (1981). Rebeliões da senzala: quilombos insurreição guerrilhas. São Paulo: Ciências Humanas.

Nora, P. (1993). Entre memória e história. A problemática dos lugares. Revista Projeto História. (10), 7-28.

Oliveira, A. M, \& Marinho, M. (2005). Comunidade Quilombola de Furnas do Dionísio: manifestações culturais, turismo e desenvolvimento local. Caderno Virtual de Turismo. 5(1), 23-30.

Orlandi, E. P. (2000). Análise de discurso: princípios e procedimentos. Campinas, SP: Pontes. Pollack, M. (1992). Memória e Identidade Social. Revista dos Estudos Históricos, 5(10), 200212. Rio de Janeiro.

Projeto Vida de Negro. (2002). Terra de preto no Maranhão: quebrando o mito do isolamento. São Luís: SMDH/CNN-MA/PVN.

Quivy, R., \& Champenhoudt, L. V. (2005). Manual de investigação em Ciências Sociais. Portugal: Gradiva.

Rico Cánovas, E. (2014). Em patrimonio cultural como argumento para la renovacion de destinos turísticos consolidados del litoral em la província de Alicante. Tese de Doutorado em Turismo. Universidade de Alicante, Espanha.

Rodovalho, N., Fonseca, A. C. F., \& Sousa, M. R. S. (2010). Identidade, cultura e turismo: do pertencimento ao turismo cultural. Cadernos de Educação, Tecnologia e Sociedade, 2(1). 915.

Sachs, I. (2004). Desenvolvimento includente, sustentável sustentado. Rio de Janeiro: Garamond.

Sachs, I. (2003). Inclusão social pelo trabalho: desenvolvimento humano, trabalho decente e o futuro dos empreendedores de pequeno porte. Rio de Janeiro: Garamond.

Santos, M., Souza, M. A., \& Silveira, M. L. (2002). Território: globalização e fragmentação. São Paulo: Hucitec, Annablume. 
Sen, A. (2000). Desenvolvimento como liberdade. São Paulo: Companhia das Letras.

Singer, P. (2002). Introdução à economia solidária. São Paulo: Fundação Perseu Abramo.

SANTOS, S. R., LEITE, A. R. L., ROCHA, A. H. C., \& BARBOSA, G. S. (2020). Possibilidades e realidades em comunidades Quilombolas do Maranhão: o turismo como resgate da memória e identidade. Revista de Turismo Contemporâneo, 8(2), 316-336.

https://doi.org/10.21680/2357-8211.2020v8n2ID18601 